\title{
Mikrodalga Destekli Çinko Borat Sentezi ve Karakterizasyonu
}

\author{
Hikmet Okkay ${ }^{1 *}$ \\ 1 Yalova Üniversitesi, Mühendislik Fakültesi, Kimya Mühendisliği Bölümü, Yalova, Türkiye (ORCID: 0000-0002-4711-8351), hokkay@yalova.edu.tr
}

(İlk Geliş Tarihi 15 Eylül 2020 ve Kabul Tarihi 6 Ocak 2021)

(DOI: 10.31590/ejosat.795269)

ATIF/REFERENCE: Okkay, H., (2021). Mikrodalga Destekli Çinko Borat Sentezi ve Karaktarizasyonu. Avrupa Bilim ve Teknoloji Dergisi, (21), 31-36.

\section{$\ddot{O} \mathbf{z}$}

Çinko borat, polimerik malzemeler başta olmak üzere birçok malzemenin bileşiminde, alev geciktirici ve duman önleyici özelliğinden dolayı kullanılmaktadır. Çinko boratlar, çözünebilen çinko ve bor tuzlarının sulu çözeltilerde gerçekleştirilen reaksiyonuyla ya da katı çinko oksidin borik asitle yine sulu ortamda ve yüksek sıcaklıklarda reaksiyonu ile üretilmektedir. Bu çalışmada, çinko oksit $(\mathrm{ZnO})$ ve borik asitten $\left(\mathrm{H}_{3} \mathrm{BO}_{3}\right)$, sulu ortamda gerçekleştirilen katı-sıvı faz reaksiyonu ile çinko borat üretiminde mikrodalga enerjisi kullanılarak, yöntemin reaksiyon süresi, verimi ve ürün özellikleri üzerindeki etkileri incelenmiştir. Mikrodalga destekli yöntemden elde edilen optimum reaksiyon şartları, geleneksel yöntem için kullanılarak her iki metot karşılaştırılmışıı. Mikrodalga destekli yöntemde en yüksek dönüşüm \% 92,3 olarak, 140 Watt mikrodalga gücünde, $90{ }^{\circ} \mathrm{C}$ sıcaklıkta, 120 dakika reaksiyon süresinde, 350 rpm karıştırma hızında ve 7,5:1 $\mathrm{H}_{3} \mathrm{BO}_{3}: \mathrm{ZnO}$ oranında elde edilmiştir. Optimum değerler kullanılarak gerçekleştirilen geleneksel yöntemle elde edilen çinko borat dönüşümü \% 71,5 olarak bulunmuştur. Yüksek dönüşümün yanısıra mikrodalga enerjisinin sağladı ğı homojen ve doğrudan bir ısıtma şartları ile daha uniform yapıda ve yüksek kristalinitede ürün elde edilmiştir. Buna bağlı olarak yüksek dehidrasyon hızı ile alev geciktirici özelliği daha etkin çinko borat örnekleri elde edilmiştir.

\section{Microwave Assisted Zinc Borate Synthesis and Characterization}

\begin{abstract}
Zinc borate is used in the composition of many materials, especially polymeric materials, due to its flame retardant and anti-smoke properties. Zinc borates are produced by the reaction of soluble zinc and boron salts in aqueous solutions or by the reaction of solid zinc oxide with boric acid in an aqueous medium and at high temperatures. In this study, the effects of microwave energy on reaction time, yield, and product properties in zinc borate production were investigated by solid-liquid phase reaction from zinc oxide (ZnO) and boric acid $\left(\mathrm{H}_{3} \mathrm{BO}_{3}\right)$ in the aqueous medium. The optimum reaction conditions obtained from the microwave assisted method were used for the conventional method and both methods were compared. The highest conversion as 92,3\% was obtained in the microwave assisted method, at 140 Watt microwave power, $90^{\circ} \mathrm{C}$ temperature, 120 minutes reaction time, $350 \mathrm{rpm}$ stirring speed, and $7.5: 1$ $\mathrm{H}_{3} \mathrm{BO}_{3}$ : $\mathrm{ZnO}$ ratio. The zinc borate conversion obtained by the conventional method using optimum values was found to be $71.5 \%$. In addition to high conversion, a homogeneous and direct heating conditions provided by microwave energy yielded a more uniform structure and high crystallinity. Accordingly, as a result of the high dehydration rate, zinc borate samples with more effective flame retardant properties were obtained.
\end{abstract}

Keywords: Microwave energy, Zinc Borate, Boric acid, Flame retardant.

\footnotetext{
* Sorumlu Yazar: Yalova Üniversitesi, Mühendislik Fakültesi, Kimya Mühendisliği Bölümü, 77200, Yalova, Türkiye, ORCID: 0000-0002-47118351, hokkay@yalova.edu.tr
} 


\section{Giriş}

Endüstride birçok uygulama alanı bulunan Çinko borat, özellikle pvc, halojenli polyester ve naylonlarda alev geciktirici, duman bastırıcı ve korozyon önleyici olarak kullanılmakta olup bununla birlikte yüksek sıcaklıklara dayanıklı plastik malzemelerin imalatında, elektrik/elektronik parçalarda, kablolarda, yanmaya dayanıklı boyalarda, tekstil ve kâğıt endüstrisinde de sıklıkla kullanılmaktadır (İpek, 2020). Çinko borat, ısıya maruz kaldığında, yanıcı malzemelerin salınmasını engelleyen bir karbonizasyon oluşumu sağlar ve ayrıca yapısında bulunan bağlı suyun dehidrasyonu ile alev geciktirici ve duman bastırıcı özellik gösterir (Ata ve ark., 2011). Yapısında bulunan Çinko, Bor ve $\mathrm{Su}$ oranlarına bağlı olarak birçok farklı formülasyonu bulunmakla beraber yüksek alev geciktirici özelliklerinden dolay1 genellikle $2 \mathrm{ZnO} \cdot 3 \mathrm{~B}_{2} \mathrm{O}_{3} \cdot 3.5 \mathrm{H}_{2} \mathrm{O}$ ve $2 \mathrm{ZnO} \cdot 3 \mathrm{~B}_{2} \mathrm{O}_{3} \cdot 7 \mathrm{H}_{2} \mathrm{O}$ molar oranına sahip olanlar daha çok kullanılmaktadır (Ting ve ark.,2009). Bu molar orandaki farklılıklar reaksiyon şartlarına bağlı olarak değişmektedir. Çinko borat genellikle çinko oksit ile borik asidin reaksiyonu ile üretilir (Cui ve ark.,2012).

$$
6 \mathrm{H}_{3} \mathrm{BO}_{3(\mathrm{aq})}+2 \mathrm{ZnO}_{(\mathrm{k})} \rightarrow 1\left(2 \mathrm{ZnO} \cdot 3 \mathrm{~B}_{2} \mathrm{O}_{3} \cdot 3.5 \mathrm{H}_{2} \mathrm{O}\right)_{(\mathrm{k})}+5.5 \mathrm{H}_{2} \mathrm{O}
$$

Günümüzde ürün özelliklerini geliştirmek, reaksiyonları hızlandırmak, maliyetleri azaltmak gibi çeşitli avantajları sağlamak için birçok proses ve reaksiyonda, mikrodalga enerjisinden faydalanılmaktadır (Nüchter ve ark.,2003). Mikrodalga enerjisi, elektrik ve manyetik alan komponentleri ihtiva eden elektromagnetik dalgalardır. Elektromagnetik dalga olduklarından dolayı birbirine dik yönde etkiyen elektrik ve manyetik alan bileşenlerine sahiptirler (Kuşlu ve Çavuş, 2008). Bir yağ banyosu veya benzeri bir cihaz kullanarak dolaylı enerji aktarımının aksine, mikrodalga enerjisinin reaksiyon karışımı ile doğrudan etkileşimi ile çok kısa bir sürede reaksiyonlar gerçekleştirme olasılığı, enerji tüketimindeki azalmanın yanısıra zaman tasarrufu sağlamasıyla verimlilik artışına önemli katkılar sağlamaktadır (Dallinger ve Kappe, 2007; Bekdeşer, 2019; Akyüz ve ark., 2015).

Mikrodalga ışımasının kimyasal reaksiyonlardaki etkisi, termal etki (aşırı 1sınma, sıcak noktalar ve seçici 1sıtma) ve termal olmayan etkinin (yüksek polarizasyon) bir kombinasyonudur ve bu etkilerin bir sonucu olarak hareketlilik ve difüzyonun artması moleküllerin birbirleriyle etkili bir şekilde temasını sağlamaktadır (Hoz ve ark., 2005).

Çinko borat üretimi, literatürde (Shi ve ark., 2008a; Shi ve ark., 2008b; Shi ve ark., 2009; Gönen ve ark., 2011; Eltepe ve ark., 2007; Gürhan ve ark., 2009) farklı yaklaşım ve teknikler kullanılarak incelenmiştir. Çalışmalarda, elde edilen ürünün özellikleri ve reaksiyonda etkili olan sıcaklık, karıştırma hızı, reaktan oranı, süre gibi parametreler ve optimizasyonu araştırılmıştır. Genel olarak $70{ }^{\circ} \mathrm{C}$ ile $100 \quad{ }^{\circ} \mathrm{C}$ arasında değişkenlik gösteren bir sıcaklık aralığında ve 2 ila 6 saat süren reaksiyon şartlarında elde edilebilen çinko borat için yapılan bir çalışmada (Ata ve ark., 2011), optimum reaksiyon şartları, 766 rpm karıştırma hızı, $85{ }^{\circ} \mathrm{C}$ sıcaklık, 10:1 $\mathrm{H}_{3} \mathrm{BO}_{3}: \mathrm{ZnO}$ oranı ve 183 dakika reaksiyon süresi olarak belirlenmiştir.

$\mathrm{Bu}$ çalışmada, çinko oksit $(\mathrm{ZnO})$ ve borik asitten $\left(\mathrm{H}_{3} \mathrm{BO}_{3}\right)$ sulu ortamda gerçekleştirilen katı-sıvı faz reaksiyonu ile çinko borat üretiminde mikrodalga enerjisi kullanılarak, yöntemin reaksiyon süresi, verimi ve ürün özellikleri üzerindeki etkileri incelenmiştir.

\section{Materyal ve Metot}

Denemeler için ilk olarak, borik asidin $25{ }^{\circ} \mathrm{C}$ sıcaklıktaki stokiyometrik miktarları saf suda 20 dakika karıştırılarak çözünmeleri sağlanmıştır. Çinko oksidin tam dönüşümünün sağlanması için borik asidin fazlası kullanılmıştır. Reaksiyon ortamına toplam çözelti miktarının \% 1'i olacak şekilde çinko borat eklenerek kristallenme oluşumunu başlatması sağlanmıştır. Bunu takiben, incelenmesi düşünülen oranlara göre stokiyometrik olarak hesaplanan miktarlardaki çinko oksit, borik asit (A.Aesar, \%99) çözeltisine eklenerek hem geleneksel yöntemle hem de mikrodalga destekli yöntemle reaksiyonlar gerçekleştirilmiştir. Her iki yöntem sonunda da üretilen çinko borat içerisindeki serbest olarak kalan borik asidi uzaklaştırmak maksadıyla yıkama ve kurutma işlemi uygulanmıştır.

Mikrodalga destekli yöntemde laboratuvar kullanımıma uygun hale getirilen (LG, 1200 Watt, 17 lt) mikrodalga cihazı kullanılmıştır. Reaksiyon sıcaklığı, mikrodalga ortamında kullanılabilen fiber optik sıcaklık probuna sahip sıcaklık ölçer (Optocon-TS3) ile takip edilmiştir. Mekanik karıştırma, mikrodalga ile etkileşime girmeyen teflon şaft ve kanatçık ile sağlanmıştır. Denemeler iki boyunlu $250 \mathrm{ml}$ hacmindeki balon reaktörde gerçekleştirilmiştir. Ani (aşırı) 1sınmanın önüne geçmek ve sıcaklık kontrolünün hassas bir şekilde sağlanması için mikrodalga gücü $140 \mathrm{~W}$ olacak şekilde sabit tutulmuş olup, ön denemeler ve literatür verilerinden faydalanılarak belirlenen değişken seviyelerine sahip diğer proses değişkenleri, $\left(\mathrm{H}_{3} \mathrm{BO}_{3}: \mathrm{ZnO}\right.$ oranı, süre ve karıştırma hızı), tek seferde tek değişken (one variable at a time) yöntemine göre incelenmiştir. Mikrodalga sistemlerinde izotermal şartların sağlanması güç olduğundan denemeler, reaksiyon ortamının mikrodalga enerjisini maksimum seviyede ve sürekli olarak absorblayabilmesi için, minimum mikrodalga gücünde ve tek bir sıcaklıkta, $90{ }^{\circ} \mathrm{C}$ de $\left( \pm 3{ }^{\circ} \mathrm{C}\right)$ de gerçekleştirilmiştir. Güç ve sıcaklık manuel olarak kontrol edilerek belirlenen sıcaklık değerleri +/- yönünde aşılır aşılmaz, enerji kesilip/verilerek proses gerçekleştirilmiştir.

Mikrodalga destekli yöntemden elde edilen optimum reaksiyon şartları, geleneksel yöntem için kullanılarak her iki metot karşılaştırılmıştır. Optimum şartların belirlenmesinde yanıt (response) olarak reaksiyondaki çinko oksidin dönüşümü oranı $\left(\% \mathrm{X}_{\mathrm{ZnO}}\right)$ kullanılmıştır.

Çalışmada belirlenen değişkenlerin inceleme seviyeleri tablo1 de görülmekte olup, her seri deneme sonunda belirlenen değişkenin en iyi sonuç alınan değeri, bir sonraki deneme serisinde sabit alınmak suretiyle denemeler gerçekleştirilmiştir.

Tablo 1. Mikrodalga etkisi altında çinko borat sentezi için incelenen değişkenler ve seviyeleri

\begin{tabular}{cccccc}
\hline Değişkenler & \multicolumn{2}{c}{ Düşük seviye } & \multicolumn{3}{c}{ Yüksek seviye } \\
\hline $\begin{array}{c}\mathrm{H}_{3} \mathrm{BO}_{3}: \mathrm{ZnO} \text { oranı } \\
(\%)\end{array}$ & $3: 1$ & $4,5: 1$ & $6: 1^{a}$ & $7,5: 1$ & $9: 1$ \\
$\begin{array}{c}\text { Reaksiyon süresi } \\
(\mathrm{dk})\end{array}$ & 40 & 60 & $80^{a}$ & 100 & 120 \\
$\begin{array}{c}\text { Karıştırma hızı } \\
(\mathrm{rpm})\end{array}$ & 250 & 300 & $350^{a}$ & 400 & 450 \\
\hline${ }^{a}$ Başlangıç deney koşullarl & & & &
\end{tabular}




\section{Araştırma Sonuçları ve Tartışma}

\subsection{Reaksiyon Süresinin Etkisi}

Tablo 1' de verilen değerlere göre optimum reaksiyon süresini bulmak için başlangıç deney koşullarında, farklı sürelerde denemeler gerçekleştirildi. Şekil 1'de görüldüğü gibi 140 Watt mikrodalga gücünde, $90{ }^{\circ} \mathrm{C}$ reaksiyon sıcaklığında, 6:1 $\mathrm{H}_{3} \mathrm{BO}_{3}: \mathrm{ZnO}$ oranında ve $350 \mathrm{rpm}$ karıştırma hızında, en yüksek dönüşüm 120 dakikalık deney süresinde \% 87,1 olarak elde edildi. Literatür sonuçları ile karşılaştırıldığında, uygulanan deneme şartları altında elde edilen bu dönüşüm oranı, süre açısından mikrodalga enerjisi kullanmanın oldukça etkili bir yöntem olduğunu ortaya koymaktadır. Ortalama olarak 180 ila 360 dakika aralığında tamamlanabilen reaksiyonun, mikrodalga enerjisi ile daha kısa sürelerde gerçekleşebilmesi, mikrodalga enerjisinin reaksiyon karışımı ile doğrudan etkileşimi ve bu etkileşmenin bir sonucu olarak oluşan sıcak noktaların yanısıra, hareketlilik ve difüzyonun artması ile moleküllerin birbirleriyle etkili bir şekilde temasını sağlamasının bir sonucu olarak düşünülebilir.

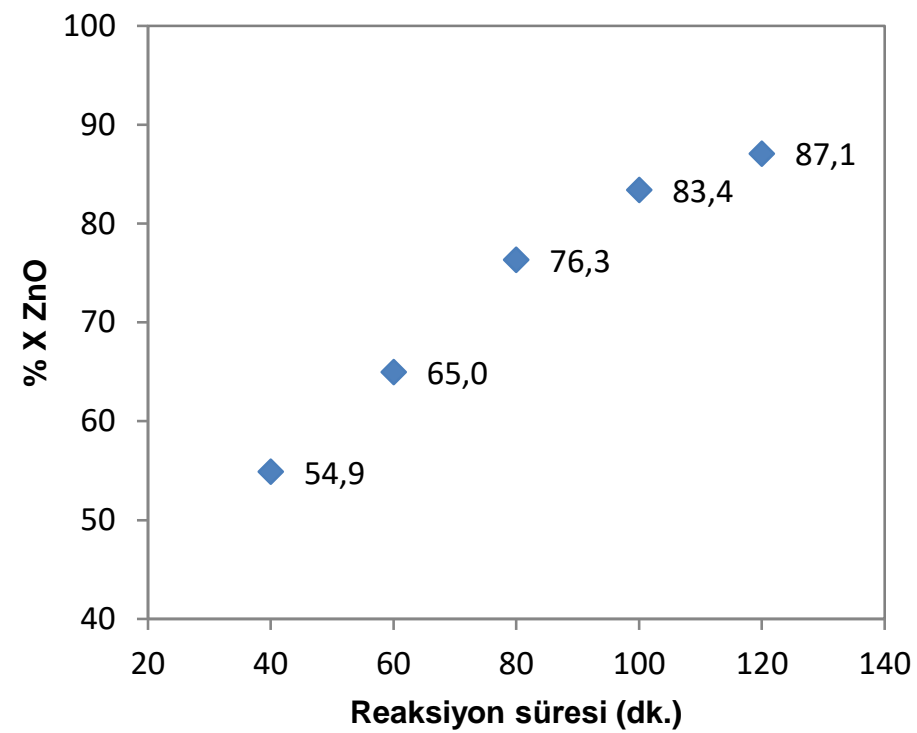

Şekil 1. Reaksiyon süresinin dönüşüme etkisi (MW: 140 Watt, $\mathrm{T}: 90^{\circ} \mathrm{C}, \mathrm{H}_{3} \mathrm{BO}_{3}: \mathrm{ZnO}$ orant: $6: 1$, Karıştırma hızı: 350 rpm)

\subsection{Karıștırma Hızının Etkisi}

Karıştırma hızının dönüşüm üzerindeki etkilerini incelemek için, ilk seri denemede en yüksek dönüşüm elde edilen 120 dakika süre, 140 Watt sabit mikrodalga gücü, $90{ }^{\circ} \mathrm{C}$ reaksiyon sıcaklığı ve $6: 1 \mathrm{H}_{3} \mathrm{BO}_{3}: \mathrm{ZnO}$ oranı değerlerinde, tablo 1 de belirlenen farklı karıştırma hızlarında denemeler gerçekleştirildi. Şekil 2 de ki grafikten incelendiğinde genel olarak karıştırma hızı arttıkça dönüşümün arttığı, fakat 350 rpm hızından sonra çokta anlamlı olamayan bir değişimin olduğu görülmektedir. Kullanılan bu deney düzeneği boyutlarında, en yüksek dönüşüm \% 87,1 ile 350 rpm karıştırma hızında elde edilmiştir.

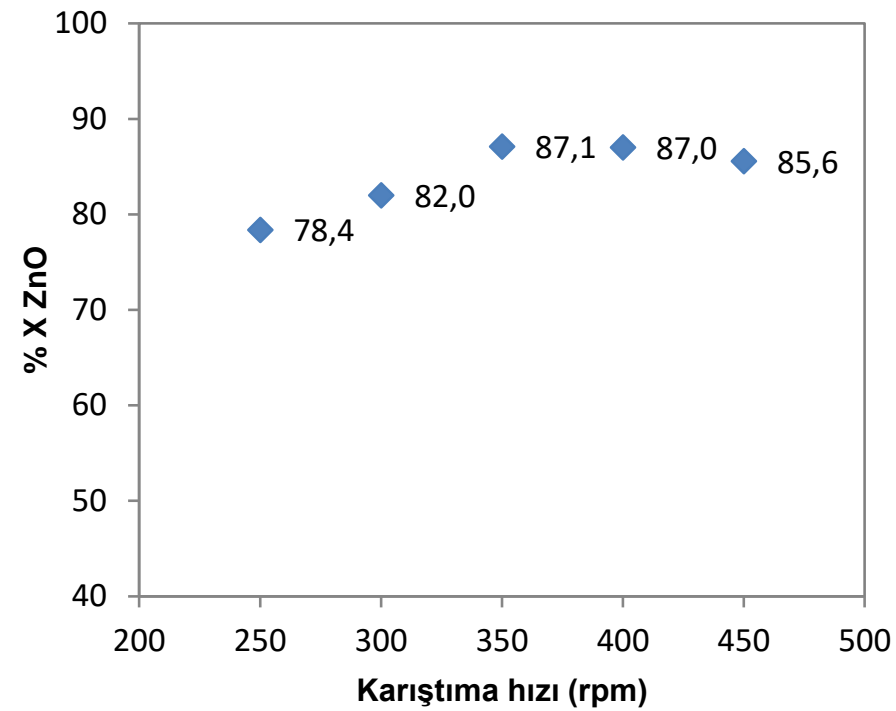

Şekil 2. Karıştırma hızının dönüşüme etkisi

(MW: 140 Watt, $\mathrm{T}: 90^{\circ} \mathrm{C}, \mathrm{H}_{3} \mathrm{BO}_{3}: \mathrm{ZnO}$ orant: $6: 1$, süre: $120 \mathrm{dk}$.)

\section{3. $\mathrm{H}_{3} \mathrm{BO}_{3}: Z n O$ Oranı Etkisi}

$\mathrm{H}_{3} \mathrm{BO}_{3}: \mathrm{ZnO}$ oranının dönüşüm üzerindeki etkilerini incelemek için, ilk iki seri denemede en yüksek dönüşüm elde edilen 120 dakika süre, 140 Watt sabit mikrodalga gücü, $90{ }^{\circ} \mathrm{C}$ reaksiyon sıcaklığı ve $350 \mathrm{rpm}$ karıştırma hızında, tablo 1 de belirlenen farkl $\mathrm{H}_{3} \mathrm{BO}_{3}: \mathrm{ZnO}$ oranı değerlerinde denemeler gerçekleştirildi. Şekil 3 de ki grafikten incelendiğinde en yüksek dönüşüm \% 92,3 ile 7,5:1 $\mathrm{H}_{3} \mathrm{BO}_{3}: \mathrm{ZnO}$ oranında elde edildiği görülmektedir. $\mathrm{Bu}$ aynı zamanda üç seri halinde yapılan denemeler içinde de elde edilen en yüksek dönüşüm olup toplu olarak bakıldığında mikrodalga enerjisi altında gerçekleştirilen çinko borat sentezi için optimum şartlar; sabit 140 Watt mikrodalga gücünde ve $90{ }^{\circ} \mathrm{C}$ de, Reaksiyon süresi 120 dakika, karıştırma hızı $350 \mathrm{rpm}$ ve 7,5:1 $\mathrm{H}_{3} \mathrm{BO}_{3}: \mathrm{ZnO}$ oranı olarak elde edilmiştir.

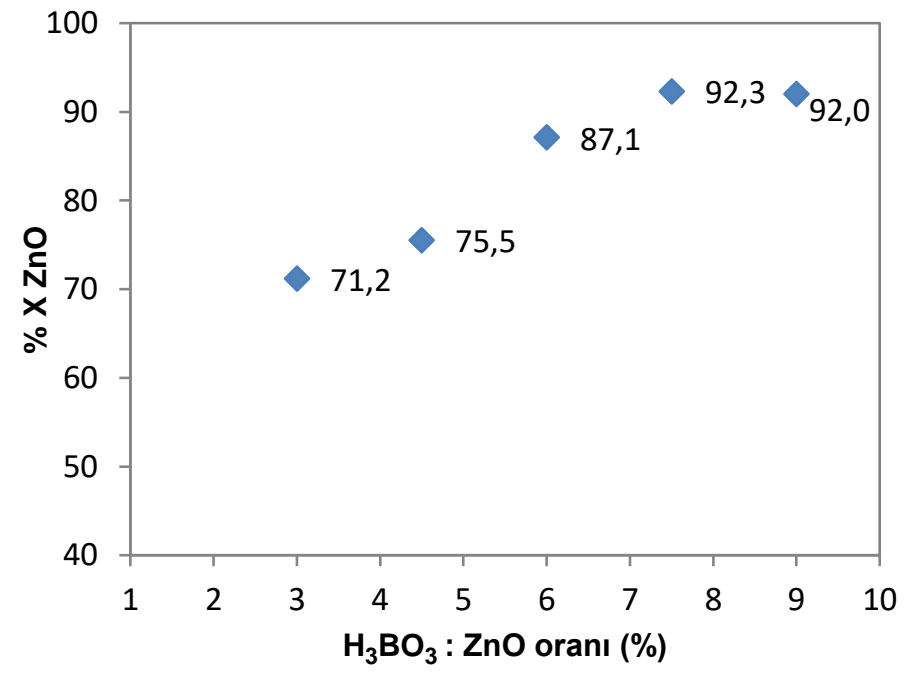

Şekil 3. $\mathrm{H}_{3} \mathrm{BO}_{3}: \mathrm{ZnO}$ oranının dönüşüme etkisi (MW: 140 Watt, $\mathrm{T}: 90^{\circ} \mathrm{C}$, Karlştırma hızı: $350 \mathrm{rpm}$, Süre:120 dakika) 


\subsection{Her İki Yöntemin Karşılaştırılması}

Geleneksel yöntem ile mikrodalga enerjisi kullanılan yöntemin karşılaştırılması için, mikrodalga yönteminden elde edilen optimum şartlar kullanılarak, aynı şartlar altında bir de geleneksel yöntemle çinko borat sentezi gerçekleştirilmiştir. Mikrodalga enerjisi kullanmadan gerçekleştirilen geleneksel yöntem ile reaksiyon dönüşüm oranı ancak \% 71,5 olarak elde edilebilmiştir. $\mathrm{Bu}$ sonuç mikrodalga destekli çinko borat üretiminin daha verimli olduğunu ortaya koymaktadır.

Tablo 2: Optimum deney şartlarında Mikrodalga ve Geleneksel yöntem ile elde edilen sonuçlar

\begin{tabular}{|c|c|c|c|}
\hline Metot & $\begin{array}{c}\% \\
\text { Dönüşüm }\end{array}$ & $\begin{array}{l}\text { Partikül tipi } \\
\text { ve boyutu }\end{array}$ & $\begin{array}{l}\text { Dehidrasyon } \\
\text { sicaklığ }\left({ }^{\circ} \mathrm{C}\right)\end{array}$ \\
\hline $\begin{array}{l}\text { Mikrodalga } \\
\text { Yöntemi }\end{array}$ & 92,3 & $\begin{array}{l}\text { Çokyüzlü } \\
\text { (polyhedral) } \\
0,1 \mu-0,4 \mu\end{array}$ & 167 \\
\hline $\begin{array}{l}\text { Geleneksel } \\
\text { Yöntem }\end{array}$ & 71,5 & $\begin{array}{l}\text { Çubuk (rod) } \\
0,1 \boldsymbol{x} 0,5 \mu \\
\text { Çokyüzlü } \\
\text { (polyhedral) } \\
0,3 \mu-0,6 \mu\end{array}$ & 162 \\
\hline
\end{tabular}

Verim açısından karşılaştırılan iki yöntemin, elde edilen ürün özellikleri üzerindeki etkilerini de incelemek için, her iki yöntemle elde edilen çinko borat örneklerinin SEM (Quanta FEG 450), TGA (Seiko, TG/DTA 6300) ve XRD (Bruker) analizleri gerçekleştirilmiştir.
Şekil 4 teki SEM görüntüleri incelendiğinde, geleneksel yöntemle elde edilen çinko boratın yer yer aglomere olmuş, ortalama olarak $0,1 \mu x 0,5 \mu$ boyutlarında çubuk ve $0,3 \mu-0,6 \mu$ boyutlarında çok yüzlü şekillerinin bir karışımı olduğu görülmekte, buna karşın mikrodalga yöntemiyle elde edilen çinko boratın ise ortalama $0,1 \mu-0,4 \mu$ boyutlarında genel olarak çok yüzlü şeklinde ve nispeten uniform dağılımlı partiküllerden oluştuğu görülmektedir. Bu durum, mikrodalganın daha homojen ve doğrudan bir 1sıtma sağlayabilmesi ile açıklanabilir.

$0.15405 \mathrm{~nm}$ dalga boyunda ve $\mathrm{Cu} / \mathrm{K}-\alpha$ radyasyonlu difraktometrede $40 \mathrm{kV}$ ve $20 \mathrm{~mA}$ değerinde, 20 ila $90^{\circ}$ aralığında $4^{\circ}$ dak. $^{-1}$ tarama hızında ölçümleri gerçekleştirilen numunelerin XRD diyagramları şekil 5 te görülmektedir. Her iki yöntemle elde edilen çinko borat numunelerinin XRD diyagramları incelendiğinde, veritabanı sonuçlarına göre elde edilen bileşiğin $3 \mathrm{ZnO} \cdot 3 \mathrm{~B}_{2} \mathrm{O}_{3} \cdot 3.5 \mathrm{H}_{2} \mathrm{O}$ yapısında olduğu anlaşılmaktadır. Piklerin şiddet ve şekilleri incelendiğinde mikrodalga yöntemi ile elde edilen çinko boratın piklerinin, geleneksel yöntemle elde edilen çinko borat piklerine göre daha keskin ve daha şiddetli olduğu görülmekte, buda mikrodalga enerjisi ile aynı şartlarda daha yüksek kristalinitede ürün elde edilebileceğini göstermektedir.

Şekil 6 da her iki yöntemle elde çinko borat örneklerinin TGA-DTG grafikleri görülmektedir. Grafikler incelendiğinde geleneksel yöntemle elde edilen çinko boratın dehidrasyon sıcaklığı ile mikrodalga destekli yöntemle elde edilen çinko boratın dehidrasyon sicaklığı sırasıyla $162{ }^{\circ} \mathrm{C}$ ve $167{ }^{\circ} \mathrm{C}$ olduğu görülmektedir. Dehidrasyon sıcaklıkları birbirine yakın olmasına karşın, her iki numunenin zamanla ağırlık kaybı hızı karşılaştırıldığında, mikrodalga destekli yöntemle elde edilen çinko boratın ağırlık kayıp hızının geleneksel yöntemle elde edilen çinko borat ağırlık kayıp hızından 1,5 kat daha fazla olduğu görülmektedir. Buda mikrodalga destekli yöntemle daha etkili dehidrasyon özelliğine sahip çinko borat elde edilebileceğine ve bundan dolayı da daha etkili alev geciktirici özelliğe sahip ürün üretilebileceğini göstermektedir.
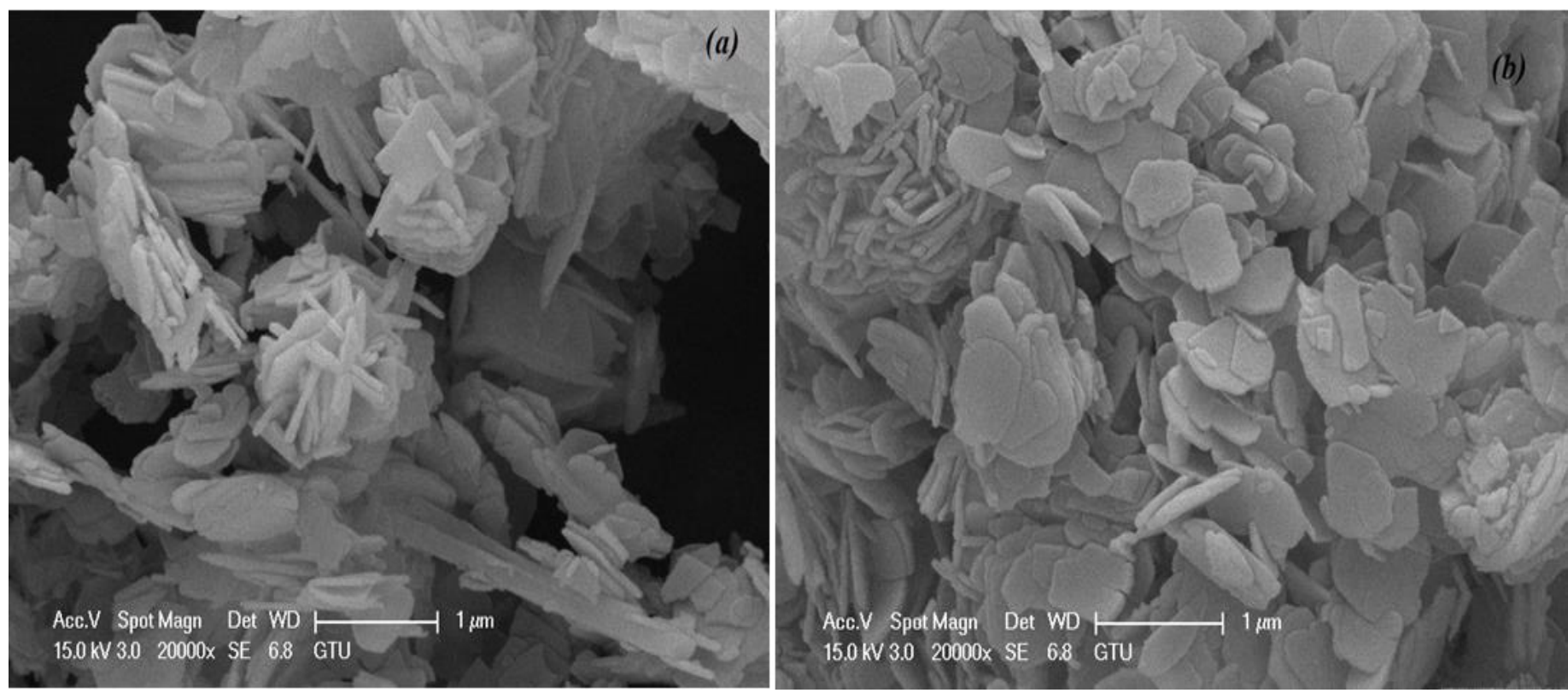

Şekil 4. Her iki yöntemle elde edilen çinko boratların SEM görüntüleri

(a) Geleneksel Yöntem (b) Mikrodalga Destekli Yöntem 

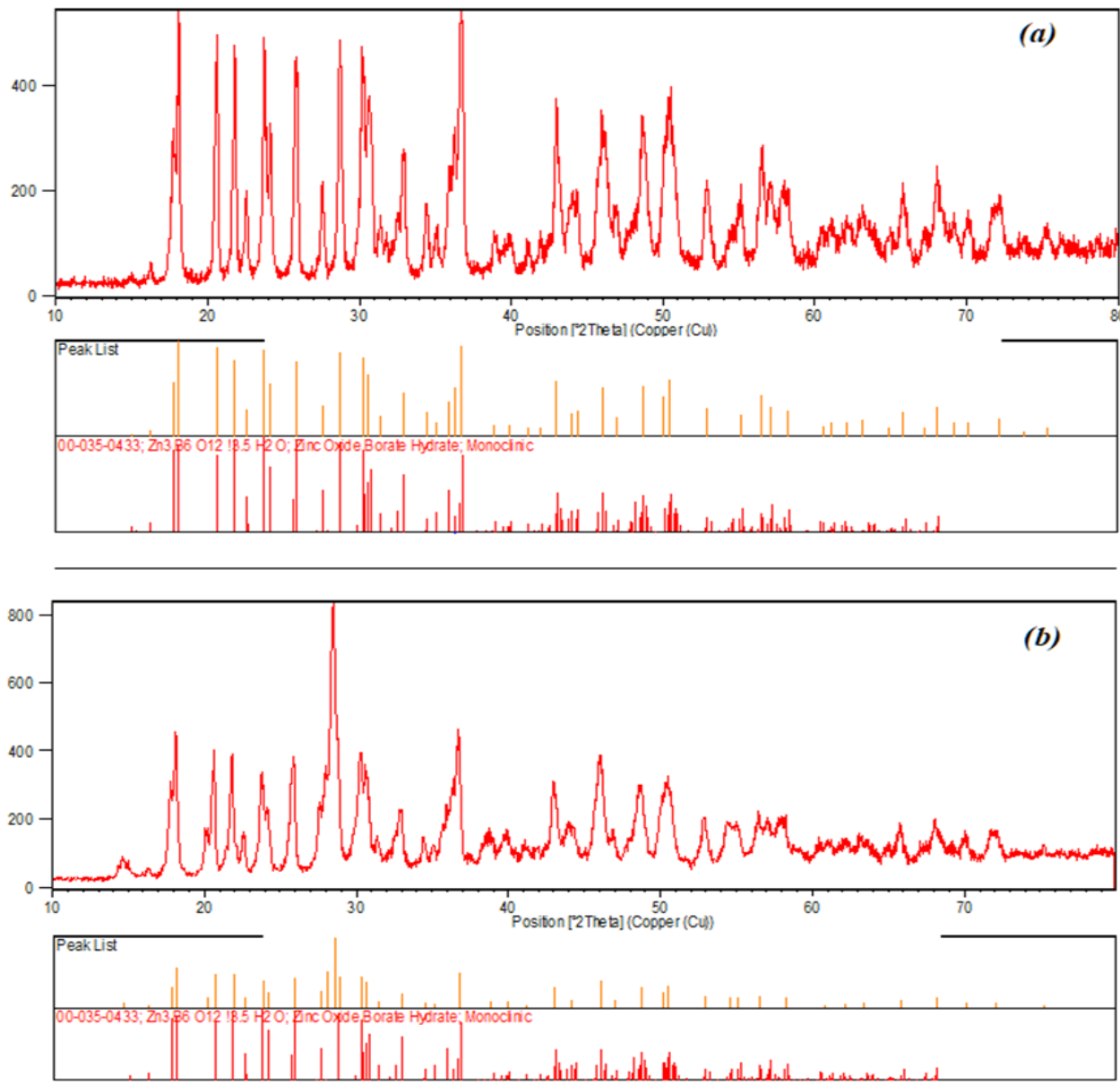

Şekil 5. Her iki yöntemle elde edilen çinko boratların XRD grafikleri

(a) geleneksel yöntem, (b) mikrodalga destekli yöntem
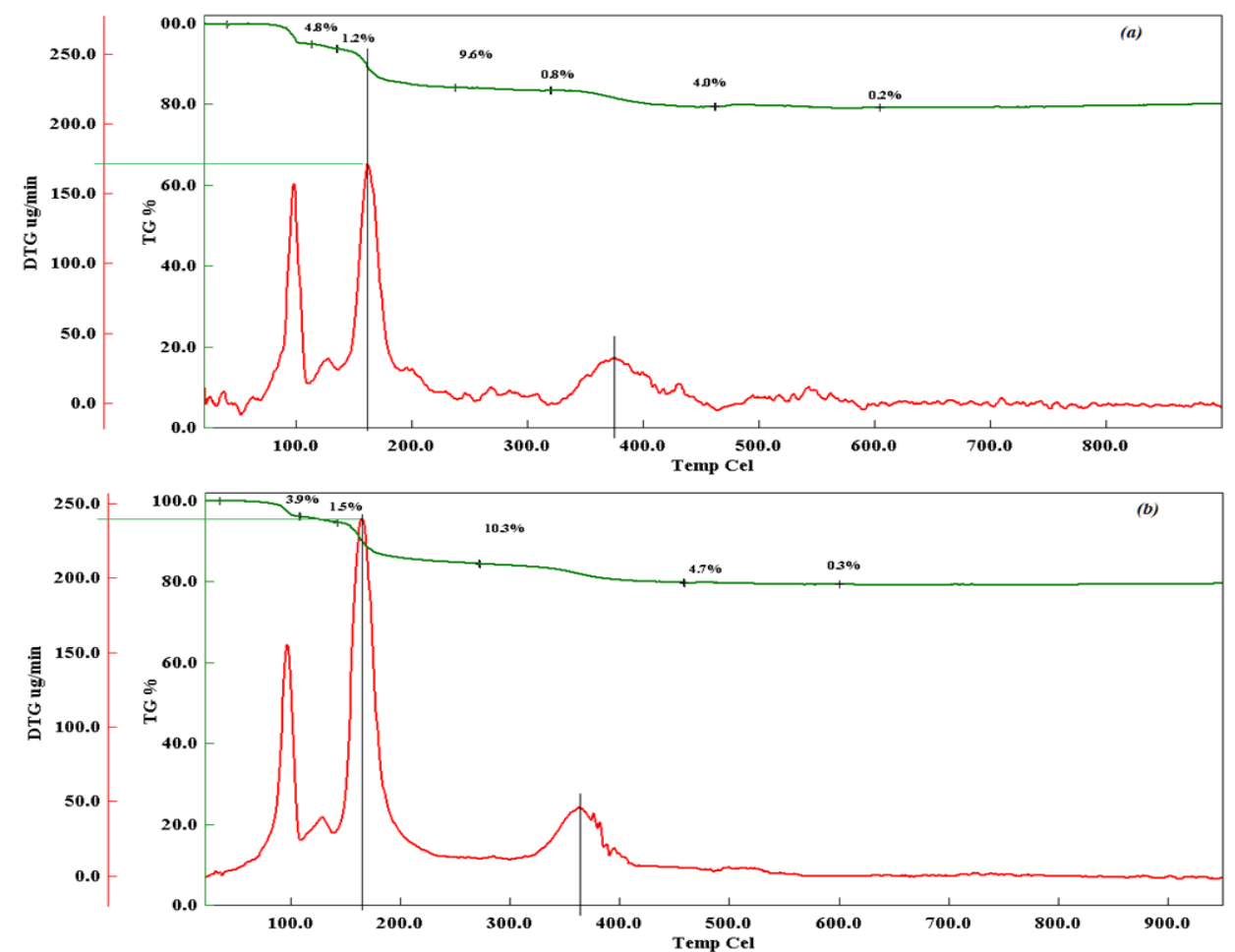

Şekil 6. Her iki yöntemle elde edilen çinko boratların TGA-DTG grafikleri (a) geleneksel yöntem, (b) mikrodalga destekli yöntem 


\section{Sonuç}

Çalışmada, endüstride başta alev geciktirici olmak üzere birçok kullanım alanı bulunan çinko borat, mikrodalga enerjisi kullanılarak sentezlendi. Mikrodalga etkisi altında gerçekleştirilen yöntem için optimum reaksiyon şartlar tespit edildi. Elde edilen optimum değerler ile geleneksel yöntemle de sentez yapılıp her iki yöntemle elde edilen ürün karşılaştırıldı. Mikrodalga destekli yöntemde en yüksek dönüşüm \% 92,3 olarak, 140 Watt mikrodalga gücünde, $90{ }^{\circ} \mathrm{C}$ de, 120 dakika reaksiyon süresinde, $350 \mathrm{rpm}$ karıştırma hızında ve 7,5:1 $\mathrm{H}_{3} \mathrm{BO}_{3}: \mathrm{ZnO}$ oranında elde edildi. optimum değerler kullanılarak gerçekleştirilen geleneksel yöntemle elde edilen çinko borat dönüşümü \% 71,5 olarak bulundu. $\mathrm{Bu}$ sonuç mikrodalga kullanımı ile daha az enerji harcanarak daha yüksek dönüşümde ürün elde edilebileceğini ortaya koymaktadır. Yüksek dönüşümün yanısıra mikrodalga enerjisinin sağladığı homojen ve doğrudan 1sıtma şartları ile daha uniform yapıda ve yüksek kristalinitede ürün elde edilmiștir. Buna bağlı olarak yüksek dehidrasyon hızı ile alev geciktirici özelliği daha etkin çinko borat örnekleri elde edilmiştir.

\section{Kaynakça}

Akyüz, G., Yılmaz, F., Menteşe, E., (2015). Microwave-assisted synthesis of some Benzimidazole derivates containing Imine function. European Journal of Science and Technology, 2(4):123-127.

Ata, O.N., Şayan, E., Engin, B., (2011). Optimization and modeling of zinc borate $2 \mathrm{ZnO} \cdot 3 \mathrm{~B}_{2} \mathrm{O}_{3} \cdot 3.5 \mathrm{H}_{2} \mathrm{O}$ production with the reaction of boric acid and zinc oxide. Journal of Industrial and Engineering Chemistry, 17:493-497.

Bekdeşer, B., (2019). Yanıt yüzey metodolojisi kullanılarak dulavratotu (Arctium Lappa)'dan antioksidanların mikrodalga destekli ekstraksiyonunun modellenmesi ve optimizasyonu. European Journal of Science and Technology, 17:655-662.

Cui, Y., Liu, X., Tian, Y., Wang, N.Z., (2012). Controllable synthesis of three kinds of zinc borates and flame retardant properties in polyurethane foam. Colloids and Surfaces A: Physicochemical and Engineering Aspects, 414:274-280.

Dallinger, D., Kappe, C.O., (2007). Microwave-assisted synthesis in water as solvent. Chemical Reviews, 107:25632591.

Eltepe, H.E., Balkose, D., Ülkü, S., (2007). Effect of temperature and time on zinc borate species formed from zinc oxide and boric acid in aqueous medium. Industrial and Engineering Chemistry Research, 46:2367-2371.

Gönen, M., Balköse, D., Ülkü, S., (2011). Supercritical ethanol drying of zinc borates of $2 \mathrm{ZnO} \cdot 3 \mathrm{~B}_{2} \mathrm{O}_{3} \cdot 3 \mathrm{H}_{2} \mathrm{O}$ and $\mathrm{ZnO} \cdot \mathrm{B}_{2} \mathrm{O}_{3} \cdot 2 \mathrm{H}_{2} \mathrm{O}$. The Journal of Supercritical Fluids, 59:43-52.

Gürhan, D., Çakal, G.O., Eroğlu, I., Ozkar, S., (2009). Improved synthesis of fine zinc borate particles using seed crystals. Journal of Crystal Growth, 311:1545-1552.

Hoz, A., Ortiz, A. D., Moreno, A., (2005). Microwaves in organic synthesis. Thermal and non-thermal microwave effects. Chemical Society Reviews, 34:164-178.

İpek, Y., (2020). Effect of surfactant types on particle size and morphology of flame-retardant zinc borate powder. Turkish Journal of Chemistry, 44:214-223.

Kuşlu, S., Çavuş, F., (2008). Mikrodalga enerjisinin analitik kimya sahasında ve katalizör hazırlamada kullanımı.
Pamukkale Üniversitesi Mühendislik Bilimleri Dergisi, 14(3):267-277.

Nüchter, M., Müller, U., Ondruschka, B., Tied, A., Launtenschlager, W., (2003). Microwave - Assisted Chemical Reactions. Chem. Engineering Technology, 26:1207-1216.

Shi, X., Xiao ,Y., Li, M., Yuan, L., Sun, J., (2008a). Synthesis of an industrially important zinc borate, $2 \mathrm{ZnO} \cdot 3 \mathrm{~B}_{2} \mathrm{O}_{3} \cdot 3 \mathrm{H}_{2} \mathrm{O}$, by a rheological phase reaction method. Powder Technology, 186:263-266.

Shi, X., Yuan, L., Sun, X., Chang, C., Sun, J., (2008b). Controllable synthesis of $4 \mathrm{ZnO} \cdot \mathrm{B}_{2} \mathrm{O}_{3} \cdot \mathrm{H}_{2} \mathrm{O}$ nanomicrostructures with different morphologies: influence of hydrothermal reaction parameters and formation mechanism. Journal of Physical Chemistry C, 112:35583567.

Shi, X., Xiao, Y., Yuan, L., Sun, J., (2009). Hydrothermal synthesis and characterizations of $2 \mathrm{D}$ and $3 \mathrm{D}$ $4 \mathrm{ZnO} \cdot \mathrm{B}_{2} \mathrm{O}_{3} \cdot \mathrm{H}_{2} \mathrm{O}$ nano-microstructures with different morphologies. Powder Technology, 189:462-465.

Ting, C., Cheng, D.J., Shuo, W.L., Gang, F., (2009). Preparation and characterization of nano-zinc borate by a new method. Journal of Materials Processing Technology, 209:40764079. 